\title{
Mineral stress affects the cell wall composition of grapevine (Vitis vinifera L.) callus
}

\author{
João C. Fernandes ${ }^{a}$, Penélope García-Angulo ${ }^{b}$, Luis F. Goulao ${ }^{c}$, José L. Acebes ${ }^{b}$, Sara Amâncio ${ }^{a, *}$ \\ a DRAT/CBAA, Instituto Superior de Agronomia, Universidade Técnica de Lisboa, Tapada da Ajuda, 1349-017 Lisbon, Portugal \\ b Departamento de Biología Vegetal, Área de Fisiología Vegetal, Universidad de León, E-24071 León, Spain

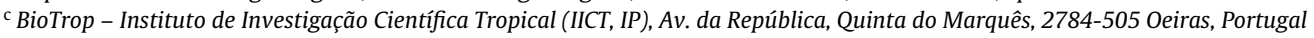

\section{A R T I C L E I N F O}

\section{Article history:}

Received 8 October 2012

Received in revised form 15 January 2013

Accepted 19 January 2013

Available online 6 February 2013

\section{Keywords:}

Cellulose

FT-IR

Lignin

Mineral stress

Pectin

\begin{abstract}
A B S T R A C T
Grapevine (Vitis vinifera L.) is one of the most economically important fruit crops in the world. Deficit in nitrogen, phosphorus and sulfur nutrition impairs essential metabolic pathways. The influence of mineral stress in the composition of the plant cell wall $(\mathrm{CW})$ has received residual attention. Using grapevine callus as a model system, 6 weeks deficiency of those elements caused a significant decrease in growth. Callus CWs were analyzed by Fourier transform infrared spectroscopy (FT-IR), by quantification of CW components and by immunolocalization of CW epitopes with monoclonal antibodies. PCA analysis of FT-IR data suggested changes in the main components of the $\mathrm{CW}$ in response to individual mineral stress. Decreased cellulose, modifications in pectin methyl esterification and increase of structural proteins were among the events disclosed by FT-IR analysis. Chemical analyses supported some of the assumptions and further disclosed an increase in lignin content under nitrogen deficiency, suggesting a compensation of cellulose by lignin. Moreover, polysaccharides of callus under mineral deficiency showed to be more tightly bonded to the $\mathrm{CW}$, probably due to a more extensive cross-linking of the cellulose-hemicellulose network. Our work showed that mineral stress impacts the CW at different extents according to the withdrawn mineral element, and that the modifications in a given CW component are compensated by the synthesis and/or alternative linking between polymers. The overall results here described for the first time pinpoint the CW of Vitis callus different strategies to overcome mineral stress, depending on how essential they are to cell growth and plant development.
\end{abstract}

(c) 2013 Elsevier Ireland Ltd. All rights reserved.

\section{Introduction}

The structural and mechanical support of plants is provided by cell walls (CWs), which are load-bearing, extensible viscoelastic structures that surround the cells, acting as an "exoskeleton". The CW plays a vital role in the regulation of the rate and direction of growth and the morphology of plant cells and organs [1]. The plant $\mathrm{CW}$ is a dynamic complex with further functions such as control of the diffusion through the apoplast, signaling, regulation of cellto-cell interactions, storage of carbohydrates, or protection against biotic [2] and abiotic stress agents [3].

Abbreviations: 2.4-D, 2,4-dichlorophenoxy-acetic acid; CDTA, cyclohexanetrans-1.2-diamine- $N, N, N^{\prime}, N^{\prime}$-tetraacetic acid sodium salt; CW, cell wall; FT-IR, Fourier-transform infrared; GC, gas chromatography; HRP, horseradish peroxidase; MS, Murashige and Skoog Medium; -N, nitrogen deficient callus; -P, phosphorus deficient callus; PBS, phosphate buffered saline; PCA, principal component analysis; PVP-40T, polyvinylpyrrolidone; RG-I, rhamnogalacturonan-I; -S, sulfur deficient callus; SD, standard deviation; TFA, trifluoroacetic acid.

* Corresponding author. Tel.: +351 213653418; fax: +35133653383.

E-mail address: samport@isa.utl.pt (S. Amâncio).
In the primary $\mathrm{CW}$, cellulose is the main load-bearing polysaccharide which interlinks with cross-linking matrix glycans, predominantly xyloglucan in dicots [4], to form an extensive framework that provides most of the tensile strength to the CW matrix. This network is embedded in a surrounding phase constituted by pectic polysaccharides, forming hydrophilic gels that determine the regulation of the hydration status and ion transport, the definition of the porosity, stiffness and control of the wall permeability [5]. These features are, in turn, defined by the chemical structure of pectic polysaccharides, particularly the branching degree and pattern, the decoration with neutral sugars and the degree and pattern of acetyl-and methyl-esterification, which can lead to either stiffening or loosening of the $\mathrm{CW}$ [6]. The occurrence of micro-domains inside the pectic polysaccharides means the localization of precise areas with distinct properties, providing a highly fine-tuned regulation of the wall properties to cope with the cell functioning. In addition to polysaccharides, a third network composed by structural glycoproteins contributes to the biophysical properties of the primary CW and cell adhesion $[7,8]$. In some tissues, after cell growth has ceased, a secondary CW is formed with higher cellulose content and a different organization of its deposition. After cellulose, lignin is 
the second most abundant plant polymer in vascular plants [9]. In secondary CWs, lignin is deposited within, around or among the cellulose microfibrils establishing covalent bonds with carbohydrates, providing additional strength and rigidity that, along evolution, allowed plants to grow upward [10].

The most consensual dicot primary CW model has been the "tethered network", a representation in which the hemicellulose polymers link cellulose through hydrogen bonds to create a load bearing tether, inserted in an amorphous cement-like pectin matrix [11]. However, recent results disclosed the presence of covalent linkages between rhamnogalacturonan-I (RG-I)-arabinan side-chains and cellulose microfibrils [12] and covalent linkages between xyloglucan and pectins in muro, $[13,14]$ providing structural links between two major cell wall domains. Moreover, since not all of the cellulose microfibril surfaces are covered with xyloglucans and not all xyloglucans are adsorbed to cellulose [15-17], the existence of such other linkages within the CW is expected to maintain its structure.

During development, the fine structure of the plant CW matrix is extensively modified. The amount and composition of specific molecules and their arrangements differ among plants, organs, cell types and even in different micro-domains of the wall of a given individual cell [18].

Localized changes in CW composition and structure also provide the cell with a notable ability to tolerate abiotic stresses, such as osmotic [19] and chemical [20,21].

Deficiencies in mineral nutrition, particularly nitrogen $(\mathrm{N})$, phosphorus $(\mathrm{P})$, potassium $(\mathrm{K})$ and sulfur $(\mathrm{S})$, which are required in relatively large amounts by the plant, strongly affect the plant metabolism with subsequent impact on the plant growth, crop yield and in both nutritional and organoleptic quality of the agronomic product [22-25]. Essential nutrients are major regulators of plant growth and development due to their involvement in primary metabolic pathways, e.g. amino acid and nucleotide biosynthesis, protein phosphorylation or disulfide bonds between cysteine.

Plant development and anatomy are impacted by abiotic stresses and a common "stress-induced" set of responses have been reported: prompting of localized cell division, arrestment of cell elongation, and modifications in cell differentiation status [26].

Limited mineral nutrient availability has been reported to affect organ growth rates, through inhibition of the production of new cells and/or cell expansion [27] via reduction of CW plasticity $[28,29]$. It has been proposed that nutrient-induced stress act by modifying xylem tension which then signals the onset of CW rearrangements in growing tissues $[30,31]$. These components are determined by the dynamic regulatory properties of the CW. Nevertheless, and even though the importance of mineral nutrition in plant development has been widely recognized, only residual attention has been given to its influence on the CW dynamics. More recently, global transcriptomic studies involving nutrient depleted plants revealed differential regulation of CW-related genes and proteins in various species [32,33], emphasizing the CW role in survival response mechanisms.

Despite the grapevine (Vitis vinifera L.) economic value and scientific relevance as a model species, there is little information about the CW structure and polysaccharide composition in this species. Investigation has been mainly focused to the economic important organ, the fruit, both berry pulp and skin, reviewed in [34].

The aim of the present work was to investigate the response of the CW to mineral depletion of individual major nutrients, nitrogen, phosphorus and sulfur, using Vitis callus as experimental model. Here, an integrated approach employing complementary methodologies was followed. Fourier-transform infrared (FT-IR) spectroscopy coupled with chemometrics was used to detect changes in CW polymers and putative cross-links $[35,36]$ to retrieve the major candidate events occurring in the $\mathrm{CW}$ in response to the imposed conditions. Candidate events were further tested by chemical methods and immunochemical staining using monoclonal antibodies [37] and through the determination of monosaccharide composition of fractionated CWs. The combined use of these methodologies allowed drafting a map of CW responses to specific changes in the mineral health in Vitis callus.

\section{Material and methods}

\subsection{Cell culture and mineral stress imposition}

$V$. vinifera cv Touriga Nacional callus tissue was maintained in the dark at $25^{\circ} \mathrm{C}$, as described in Jackson et al. [38]. Four and a half grams of callus tissue was used as initial explant in medium containing MS basal salts [39] (DuchefaBiochemie, Haarlem, NL) supplemented with $2.5 \mu \mathrm{M}$ 2.4-D (2,4-dichlorophenoxy-acetic acid); $1 \mu \mathrm{M}$ kinetin; $5 \mathrm{gl}^{-1}$ PVP-40T; $20 \mathrm{gl}^{-1}$, sucrose; $2 \mathrm{gl}^{-1}$ Gelrite $^{\circledR}$, pH 5.7. The calluses were sub-cultured every 3 weeks. Four treatments were applied: full nutrients (control), nitrogen deficiency $(-\mathrm{N})$, phosphorus deficiency $(-\mathrm{P})$ and sulfur deficiency $(-\mathrm{S})$. Commercial MS was used to obtain control samples while modified MS media in which nitrates, phosphates and sulfates were substituted for chlorides were considered -N, -P and -S treatments respectively. Calluses were sub-cultured to the respective medium after 3 weeks of growing. After each culture cycle in the respective treatment medium each sample, corresponding to 10 Petri dishes $(9 \mathrm{~cm} \varnothing)$ containing four calluses, was collected to monitor growth. Based on the results obtained, 6 weeks grown callus $(2 \times 3$ weeks $)$ samples were used for CW analyses.

\subsection{Cell wall isolation}

Twenty grams of callus samples were homogenized in liquid nitrogen using a mortar and pestle, washed with cold $100 \mathrm{mM}$ potassium phosphate buffer $\mathrm{pH} 7.0(2 \times)$, and treated overnight with $2.5 \mathrm{U} \mathrm{ml}^{-1} \alpha$-amylase VI from hog pancreas (Sigma-Aldrich Co., St. Louis) at $37^{\circ} \mathrm{C}$. The suspensions were centrifuged and the pellet was sequentially washed with distilled water $(3 \times)$, acetone $(3 \times)$, methanol:chloroform $(1: 1 ; \mathrm{v} / \mathrm{v})(3 \times)$, diethylether $(2 \times)$, and then air-dried [40].

\subsection{FT-IR spectroscopy and multivariate analysis}

FT-IR analysis was performed according to the methodology described in Alonso-Simón et al. [36]. Tablets for FT-IR spectroscopy were prepared in a Graseby-Specac Press, using $2 \mathrm{mg}$ of CW samples mixed with potassium bromide $(\mathrm{KBr})(1: 100, \mathrm{w} / \mathrm{w})$ from a minimum of 11 biological replicates per treatment. Spectra were obtained on a Perkin-Elmer System 2000 FT-IR at a resolution of $1 \mathrm{~cm}^{-1}$. In order to tackle CW structure modifications, a window between 800 and $1800 \mathrm{~cm}^{-1}$, which contains information of polysaccharide characteristic linkages, was selected for analysis. Normalization and baseline-correction were made using the Perkin-Elmer IR Data manager software and the data exported to Microsoft Excel for area normalization. Principal component analysis (PCA), using Pearson coefficient for distance estimation, was performed with a maximum of four principal components using the Statistica 6.0 software package (StatSoft, Inc., USA).

\subsection{Cellulose quantification}

Cellulose was quantified by the Updegraff method [41], using the hydrolytic conditions described by Saeman et al. [42] and quantifying the glucose released by the anthrone method [43]. 


\subsection{Lignin quantification}

Klason lignin was determined using the method described by Hatfield et al. [44]. Briefly, $60 \mathrm{mg}$ of CW material was solubilized in $2 \mathrm{ml}$ of $72 \% \mathrm{H}_{2} \mathrm{SO}_{4}$ at $30^{\circ} \mathrm{C}$ for $60 \mathrm{~min}$. The solution was diluted to $2.48 \% \mathrm{H}_{2} \mathrm{SO}_{4}$ prior to secondary hydrolysis by autoclaving at $115^{\circ} \mathrm{C}$ for $60 \mathrm{~min}$. The non-hydrolyzed residue was collected by filtration and dried at $60^{\circ} \mathrm{C}$ until constant weight. The results are expressed as $\mu \mathrm{g}$ lignin $(\mathrm{mgCW})^{-1}$.

\subsection{Quantification of pectin methyl-esterification}

The extent of esterification of pectins was assessed by quantification of the released methanol using the method described by Wood and Siddiqui [45]. To each $10 \mathrm{mg}$ CW sample, $0.75 \mathrm{ml}$ distilled water and $0.25 \mathrm{ml} 1.5 \mathrm{M} \mathrm{NaOH}$ were added. The samples were incubated at room temperature for $30 \mathrm{~min}$, chilled on ice and added with $0.25 \mathrm{ml} 4.5 \mathrm{M} \mathrm{H}_{2} \mathrm{SO}_{4}$. After centrifugation, $0.5 \mathrm{ml}$ of the supernatant was mixed with $0.5 \mathrm{ml} 0.5 \mathrm{M} \mathrm{H}_{2} \mathrm{SO}_{4}$, chilled on ice and $0.2 \mathrm{ml}$ $2 \% \mathrm{KMnO}_{4}(\mathrm{w} / \mathrm{v})$ were added. The samples were allowed to stand in an ice bath for $15 \mathrm{~min}$ and added with $0.2 \mathrm{ml} 0.5 \mathrm{M}$ sodium arsenite in $0.06 \mathrm{M} \mathrm{H}_{2} \mathrm{SO}_{4}$. The samples were thoroughly mixed and left for $1 \mathrm{~h}$ at room temperature. Finally, $2 \mathrm{ml}$ acetylacetone-ammonium acetate reagent was added, tubes were vortexed, closed and heated to $59^{\circ} \mathrm{C}$ for $15 \mathrm{~min}$. After cooling to room temperature, absorbance was read at $412 \mathrm{~nm}$ and the results were expressed as $\mathrm{ml} \mathrm{CH} \mathrm{CH}_{3} \mathrm{OH}$ $(\mathrm{mgCW})^{-1}$, using methanol as standard.

\subsection{Cell wall fractionation}

CW fractionation was done according to Selvendran and O'Neill [46] with minor modifications. Dried CW were extracted at room temperature with $50 \mathrm{mM}$ cyclohexane-trans-1.2-diamine$N, N, N^{\prime}, N^{\prime}$-tetraacetic acid sodium salt (CDTA) adjusted to $\mathrm{pH} 6.5$ with $\mathrm{KOH}$, for $8 \mathrm{~h}(2 \times)$, collected by centrifugation, washed with distilled water and the combined supernatants referred to as the CDTA-soluble fraction. The residue was incubated for $18 \mathrm{~h}$ with $0.1 \mathrm{M} \mathrm{KOH}$ containing $20 \mathrm{mM} \mathrm{NaBH}_{4}$ centrifuged and the pellet washed with distilled water. The combined alkali and water supernatants were adjusted to $\mathrm{pH} 5.0$ with acetic acid. This fraction was referred to as the $0.1 \mathrm{M} \mathrm{KOH}$-soluble fraction. Then, the residue was incubated for $18 \mathrm{~h}$ in $6 \mathrm{M} \mathrm{KOH}$ containing $20 \mathrm{mM} \mathrm{NaBH}_{4}$, processed as described for the $0.1 \mathrm{M} \mathrm{KOH}$-soluble fraction, to obtain the $6 \mathrm{M} \mathrm{KOH}$-soluble fraction. All fractions were dialyzed against distilled water with a dialysis membrane of $12-14 \mathrm{kDa}$ cut-off and lyophilized.

\subsection{Total sugar and monosaccharide quantification}

Total sugars and uronic acids were determined using the phenol-sulfuric acid assay [47] and the m-hydroxybiphenyl assay [48] respectively, using glucose and galacturonic acid as standards. Neutral sugars were quantified as described by Albersheim et al. [49]. Lyophilized samples of each CW fraction were hydrolysed with $2 \mathrm{~N}$ trifluoroacetic acid (TFA) at $121^{\circ} \mathrm{C}$ for $1 \mathrm{~h}$ and the sugars were derivatized to alditol acetates and analyzed by gas chromatography (GC) using a Supelco SP-2330 $30 \mathrm{~m} \times 0.25 \mathrm{~mm} \times 0.20 \mu \mathrm{m}$ capillary column in a Perkin Elmer Autosystem gas chromatograph fitted with a flame-ionization detector. Helium $\left(2 \mathrm{ml} \mathrm{min}^{-1}\right)$ was used as the carrier gas. Sugar quantification was carried out after determination of each sugar response factor using pure rhamnose, fucose, arabinose, xylose, mannose, galactose and glucose as standards. Inositol was used as internal standard.

\subsection{Immunodot blot assays}

For immunodot assays, $1 \mu \mathrm{l}$ aliquots from CDTA-, $0.1 \mathrm{M} \mathrm{KOH-}$ and $6 \mathrm{M} \mathrm{KOH}$-soluble fractions in three replicated dilution series (1:5 dilutions) as described by García-Angulo et al. [50] were spotted onto a nitrocellulose membrane (Scheicher \& Schull, Dassel, Germany). The membranes were blocked for $2 \mathrm{~h}$ with $0.1 \mathrm{M}$ Phosphate buffered saline (PBS) containing $4 \%$ fat-free milk powder and each primary antibody (2F4, LM1, LM5 and LM6) at a 1:5 dilution. After washing with PBS, the membranes were incubated for $1 \mathrm{~h}$ with a 1:1000 dilution of an anti-rat IgG1 secondary antibody linked to horseradish peroxidase (HRP). For signal detection, the membranes were incubated with $25 \mathrm{ml}$ of deionized water, $5 \mathrm{ml}$ methanol containing $10 \mathrm{mg} \mathrm{ml}^{-1}$ 4-chloro-1-naphtol and $30 \mu \mathrm{l} \mathrm{6 \% (v/v)} \mathrm{H}_{2} \mathrm{O}_{2}$, and photographed with a digital camera.

\subsection{Statistical analysis}

Data is presented as mean values \pm standard deviation (SD). The results were statistically evaluated by variance analysis (ANOVA) and Bonferroni test as post hoc tests with a $p=0.05$ significance, to compare the treatment effect. The SigmaPlot (Systat Software Inc.) statistical package was used in the analyses.

\section{Results}

\subsection{Effect of mineral stress on callus growth}

Our main aim was to analyze the effect of nitrogen, phosphorus or sulfur nutrient depletion in grapevine $\mathrm{CW}$ composition and structure. The effect of the imposed individual mineral stresses on the functioning of the biological experimental system used was firstly assessed by measuring the growth of callus along time. The absolute growth of Vitis callus in full MS culture medium (control) and in modified MS media without nitrogen (-N), phosphorus (-P) or sulfur (-S) along two cycles of 3 weeks each is showed in Fig. 1.

After withdrawing of nutrients, the absolute growth of the callus was significantly affected in both cycles when compared to the control. During the first 3 weeks, phosphorus and sulfur depleted media affected growth in a more pronounced way than under nitrogen absence. After a second growing cycle under nutrient depletion, a more severe reduction in growth was noticed in all individual

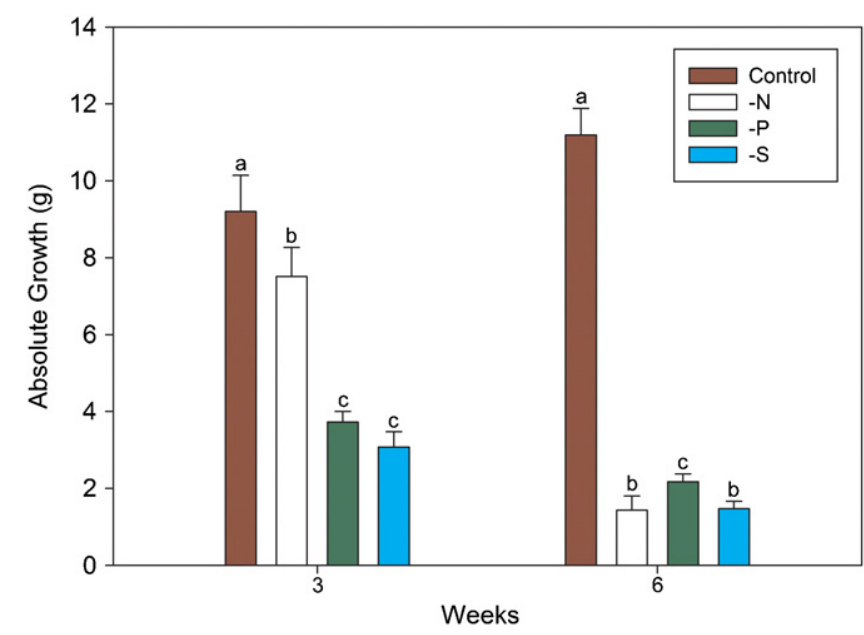

Fig. 1. Absolute growth (AG) of Vitis callus growing under nitrogen deficient (-N), phosphorus deficient $(-P)$, sulfur deficient $(-S)$ and with full nutrients (Control) for three and 6 weeks. Bars represent means of the AG of Vitis callus from 10 Petri dishes $(n=10) \pm$ SD. In each subgraph, different letters indicate significant differences at $p=0.05$. 
stresses, with a reduction in growth of ca. $80 \%$ in comparison with the control. This time scale ( 2 cycles of 3 weeks) was selected to produce template material to be used in the subsequent analyses.

\subsection{FT-IR spectroscopy determination}

Putative changes in CW relative composition during nutrient deprivation were monitored by FT-IR spectroscopy by analysis of at least 11 FT-IR CW spectra per treatment.

For a clear analysis of the FT-IR spectra a multivariate analysis (Principal Component Analysis; PCA) was performed (Fig. 2). Principal components 1 and 2 (PC1 and PC2), which explain $71.9 \%$ of the total variation, were useful to separate the samples. PC1 clearly differentiates the control samples from treatments -N and -P, while PC2 separates the samples according to each individual mineral stress. Samples from the -S treatment also tend to be discriminated from the control, considering their distribution across the gradient from the negative to the positive areas of the PC1 and PC2 axes (Fig. 2a). PC1 loading factor plot (Fig. 2b) showed several negative peaks associated with cellulose, such as $1160 \mathrm{~cm}^{-1}$, assigned to the $\mathrm{C}-\mathrm{O}$ and $\mathrm{C}-\mathrm{C}$ vibration [51], $1120 \mathrm{~cm}^{-1}$, associated with the glycosidic $\mathrm{C}-\mathrm{O}-\mathrm{C}$ vibration [52] or $988 \mathrm{~cm}^{-1}$, associated with bonds shared by cello-triose, -tetraose and -pentose [53], indicating that samples located in the negative part of PC1 (all control and some -S samples) should have a higher content of cellulose. In the same samples, an alteration in the esterification patterns of pectins is also
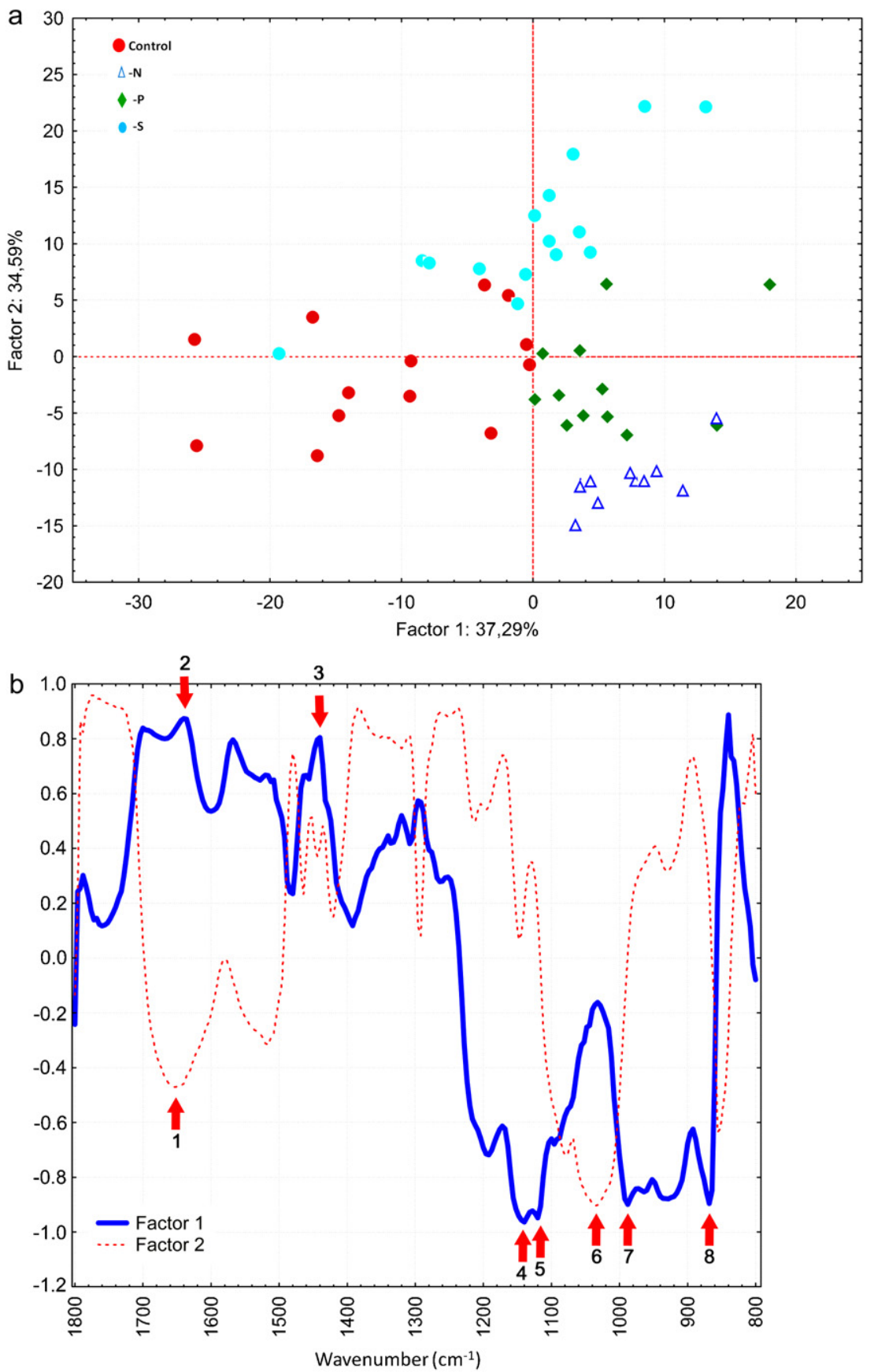

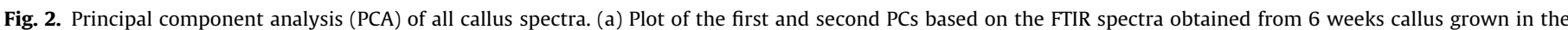

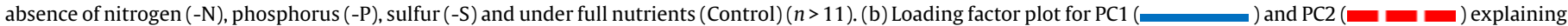

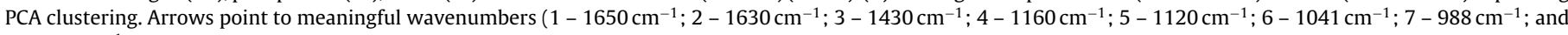
$\left.9-870 \mathrm{~cm}^{-1}\right)$. 


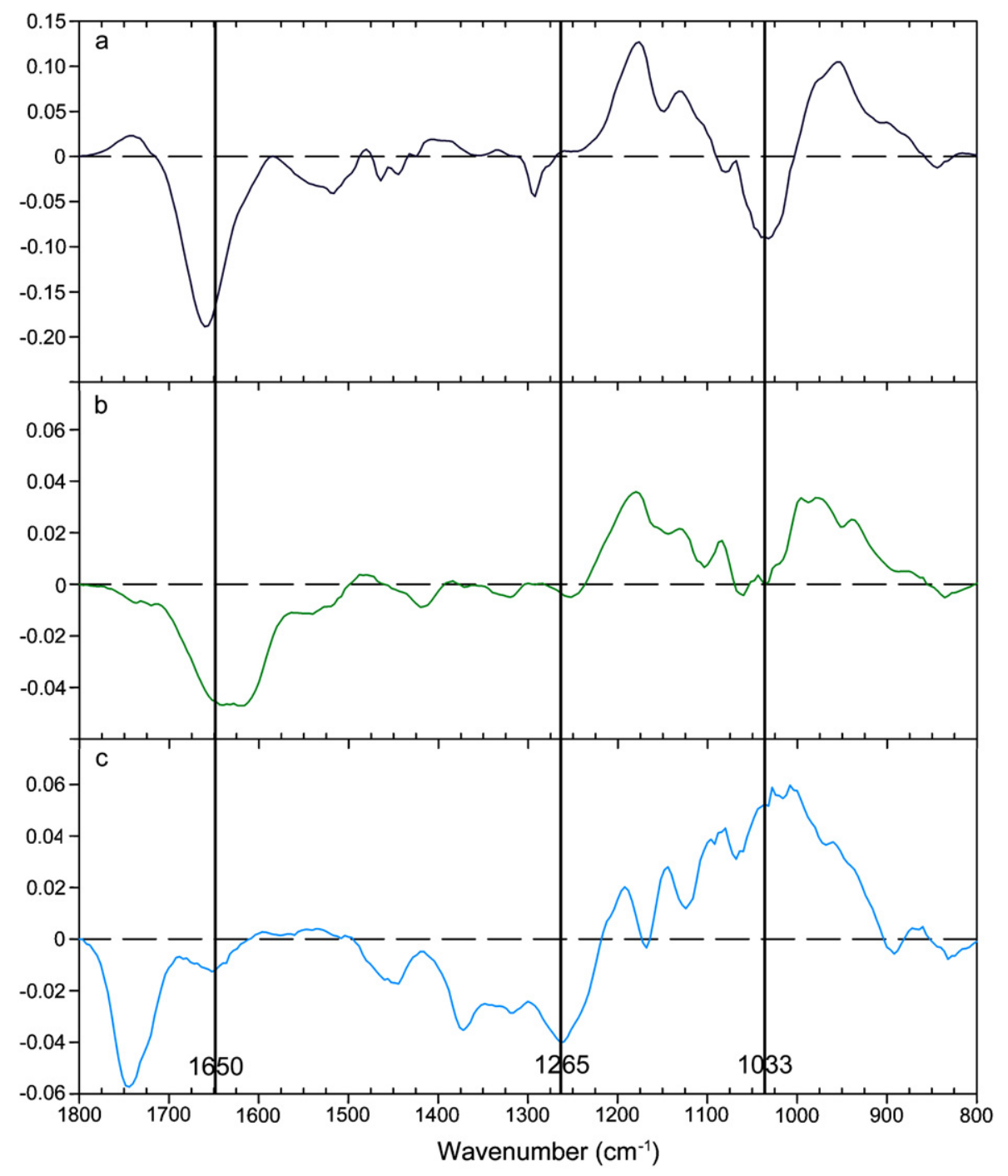

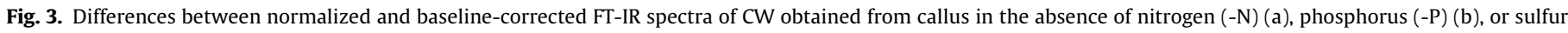
$(-S)$ (c) relative to control $(n>11)$. Vertical lines represent wavenumbers assigned to CW polymers.

suggested, as reveled by the contribution of the $950 \mathrm{~cm}^{-1}$ peak [54], indicating that the absence of nutrients alters pectin biochemistry. PC2 loading factor plot (Fig. 2b) showed negative peaks associated with xyloglucan (1041 $\mathrm{cm}^{-1}$, related to $\beta$-glucan) [52] and with proteins $\left(1650 \mathrm{~cm}^{-1}\right.$, related to $\mathrm{C}=\mathrm{O}$ amide I linkage). This evidence points to decreased concentrations of these CW components upon -N and -P conditions. PC2 positive peaks were also observed, mainly related to phenolic compounds (1630 and $1430 \mathrm{~cm}^{-1}$ ) [55], suggesting an increase of these components in CW under some mineral stresses. Other positive peaks were also observed, mainly at $840,1295,1565$ and $1700 \mathrm{~cm}^{-1}$, for factor 1 and $885,1180,1250$ and $1390 \mathrm{~cm}^{-1}$ for factor 2 , but no information is available about the nature of the linkages and wall components associated with these peaks. It should be noted that $-\mathrm{N}$ and, in a minor extent, -P callus samples tend to cluster more compactly in the plots, while control samples appear as a more dispersed group (Fig. 2a) suggesting lower variability in samples exposed to higher stresses.

To acquire additional information on the significance of spectral differences between the control and the mineral stressed callus, a subtraction of the spectra was also performed (Fig. 3). Using this approach, the differences in -N spectra observed were more striking as negative peaks in wavenumbers $1033 \mathrm{~cm}^{-1}$ characteristic of cellulose, related to deformations of $\mathrm{C}-\mathrm{OH}$ groups [52] and $1650 \mathrm{~cm}^{-1}$, assigned to proteins, as stated above. These negative peaks points to a minor amount of cellulose and proteins in $-\mathrm{N}$ condition. They were accompanied by positive peaks at 950 and $1740 \mathrm{~cm}^{-1}$, both related to a higher amount of pectins. These trends were not maintained in -P or -S conditions. In -S, alterations in cellulose assigned to the vibrations associated with the $\mathrm{CH}_{2}$ group, as revealed by the $1265 \mathrm{~cm}^{-1}$ wavenumber peak [53], were also observed (Fig. 3). A positive peak at $1180 \mathrm{~cm}^{-1}$ was also observed in all cases but it has not been associated with any known wall component or group linkage. A clear difference in the absorbance peaks for cellulose between the three treatments was observed in agreement with the PC1 separations (Fig. 2a). The overall results pinpoint cellulose and pectins as major candidates to be affected by mineral stress, what prompted us to a more detailed investigation.

\subsection{Cellulose and lignin content}

Cellulose is the main constituent of the CW. Fig. 4a shows the variation in cellulose amount in response to mineral stress imposition. A significant reduction in cellulose was observed at the extent of ca. $43 \%$ in the absence of nitrogen and, to a less extent of ca. $12 \%$, in the absence of phosphorus (Fig. 4a), when compared to the control. Sulfur depletion did not affect significantly the 

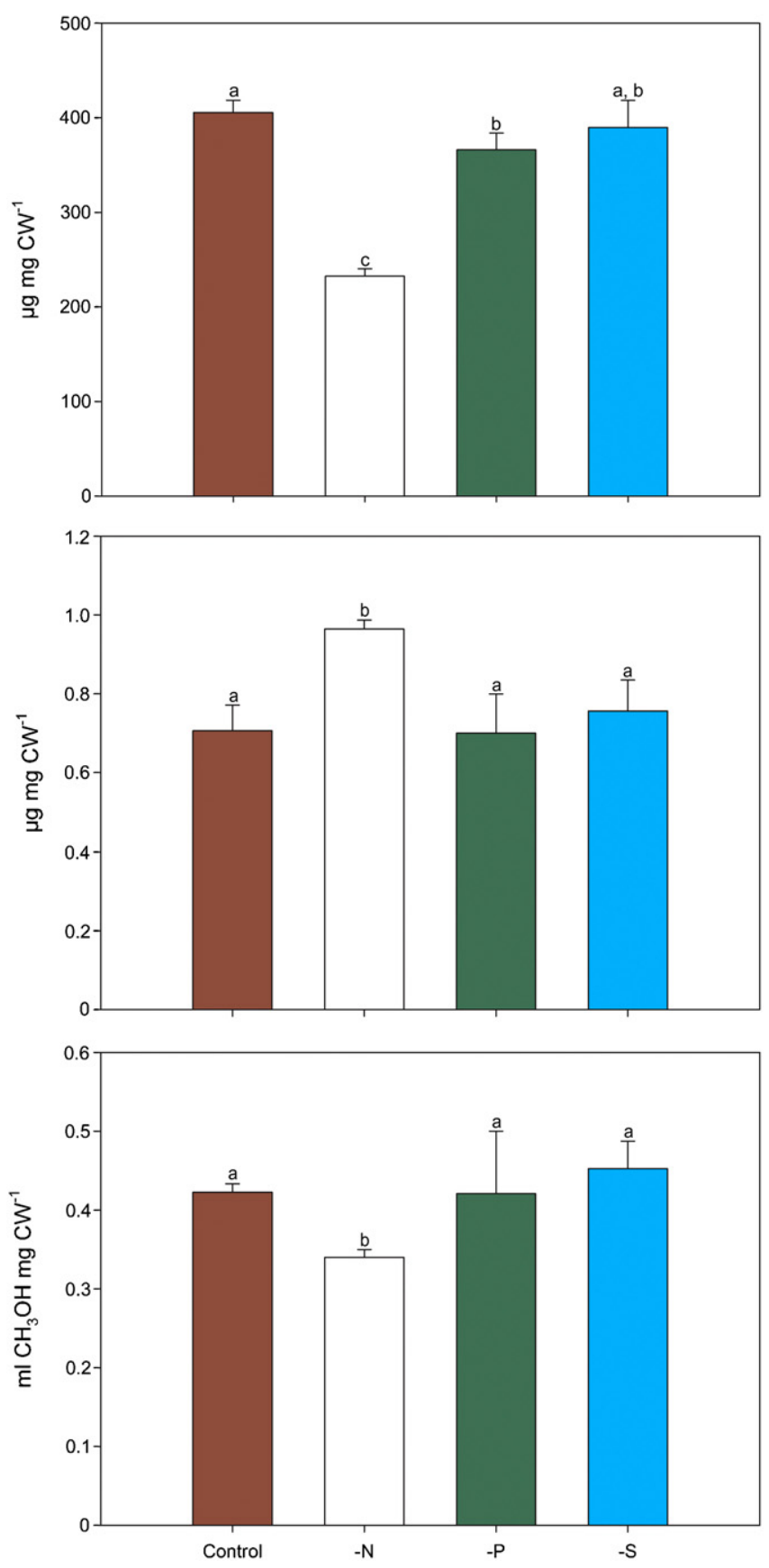

Fig. 4. (a) Cellulose content, (b) lignin content and (c) total methyl-esterification extent of 6 weeks $C W$ callus grown in nitrogen deficient $(-N)$, phosphorus deficient $(-P)$, sulfur deficient (-S) and full nutrient media (Control). Bars represent means of 6 Vitis callus $\pm \operatorname{SD}(n=10)$. Different letters indicate significant differences at $p=0.05$ significance.

synthesis or deposition of cellulose. Although lignin Klason levels were small compared with cellulose or other cell wall components, lignin quantification in control and stressed calluses reveled an increase of ca. 36\% relative to the control when nitrogen is removed from the growing medium (Fig. $4 \mathrm{~b}$ ). The absence of phosphorus and sulfur did not affect the amount of lignin in the CW of Vitis callus after 6 weeks growth.

\subsection{Degree of pectin methyl-esterification}

To further examine the putative modifications in pectin esterification suggested by FT-IR analysis, the extent of pectin methyl esterification was determined by quantification of the released methanol. The decrease in the methanol released observed in samples from callus growing under absence of nitrogen in the culture medium, indicates a lower degree of methyl esterification in comparison with the control (Fig. 4c), confirming the FT-IR results for this stress. Neither phosphorus nor sulfur absence affected the total degree of pectin esterification.

\subsection{Immunodot-blot of cell wall polysaccharide specific antibodies}

The results of immunodot assays are presented in Fig. 5. The abundance of pectins with a degree of esterification up to $40 \%$ was tested by immunodetection using 2F4 monoclonal antibody [56]. As expected, labeling was only detected in the CDTA and, to a less extent, in the $0.1 \mathrm{M} \mathrm{KOH}$-soluble fraction. A stronger signal was detected under - $\mathrm{N}$ and $-\mathrm{S}$ conditions (Fig. 5). The LM1 antibody, specific to an extensin epitope [57], showed a higher labeling under stress conditions in all soluble fractions, indicating that mineral stress increases the deposition of this structural protein. This is more striking in $-\mathrm{N}$ and $-\mathrm{S}$ conditions, the former more tightly attached to the CW. LM5 and LM6 antibodies recognize 1,4- $\beta$ galactan and $1,5-\alpha$-arabinan epitopes, respectively $[58,59]$. Under $-\mathrm{N}$, the amount of $1,5-\alpha$-arabinan and $1,4-\beta$-galactan decreases relative to the control in the CDTA-soluble fraction. A reduction of labeling was observed in the $0.1 \mathrm{M} \mathrm{KOH}$-soluble fraction in all stresses for both antibodies. Conversely, an increase in 1,5- $\alpha$ arabinan is suggested to occur under -S conditions, both in weakly and tightly CW attached polysaccharides (CDTA- and $6 \mathrm{M} \mathrm{KOH}-$ soluble fractions, respectively).

\subsection{Sugar analysis in CW fractions}

CW fractionation showed that the majority of polysaccharides were extracted from the $\mathrm{CW}$ by the strong alkaline treatment (Fig. 6). All mineral stress treatments decreased the amount of polysaccharides solubilized in CDTA and $0.1 \mathrm{M} \mathrm{KOH}$. Conversely in $6 \mathrm{M} \mathrm{KOH}$-soluble fractions, they were more abundantly detected in the $-\mathrm{N}$ and $-\mathrm{P}$ treatments (Fig. 6).

As expected, the majority of pectins (quantified as uronic acids, UA) were extracted by the CDTA and $0.1 \mathrm{M} \mathrm{KOH} \mathrm{(Fig.} \mathrm{7a} \mathrm{and} \mathrm{b).} \mathrm{GC}$ analysis of $\mathrm{CW}$ fractions showed that the more significant neutral monosaccharide present in all fractions was arabinose followed by galactose, xylose and glucose (Fig. 7a-c). The amount of uronic acids decreased in alkaline soluble fractions upon the three mineral stress treatments imposed (Fig. 7b and c).

Arabinose-containing polysaccharides responded to $-\mathrm{N}$ by decreasing its amount in weak alkaline-soluble fraction but increasing significantly in $6 \mathrm{M} \mathrm{KOH}$-soluble one. A different trend was observed for xylose- and galactose-containing polysaccharides, with a decrease in both alkaline-soluble fractions. Regarding xylose, an increase in the $6 \mathrm{M} \mathrm{KOH}$-soluble fraction was noticed in the $-\mathrm{S}$ treatment. Finally, glucose-containing polysaccharides showed increased extraction by both alkaline solutions from -P CWs.

The increase in neutral sugars observed in the $6 \mathrm{M} \mathrm{KOH}$ soluble fraction, under nitrogen starvation (Fig. 7c), is only due to the increase in arabinose, since all other monosaccharides decreased or maintain the same levels relative to control when nitrogen is withdrawn from the culture media.

\section{Discussion}

Plant model systems analyzed in controlled experimental conditions are useful tools to assess limiting nutrient situations. Using the 


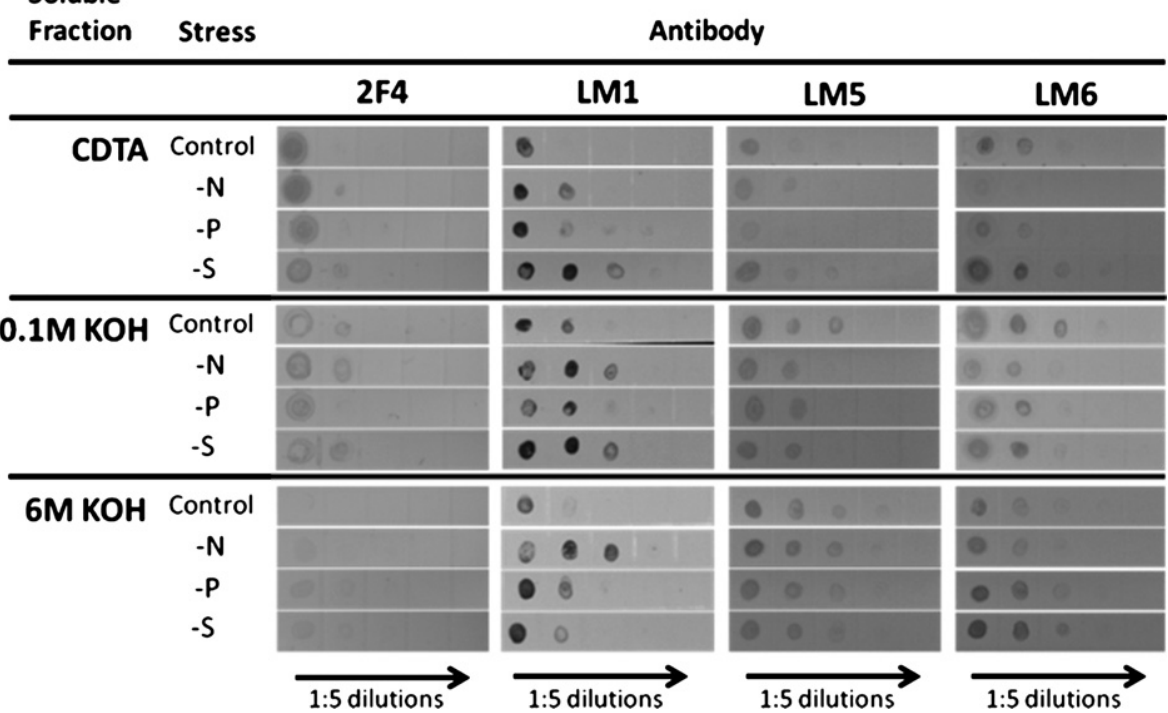

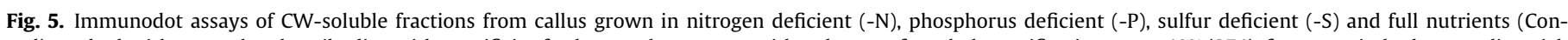

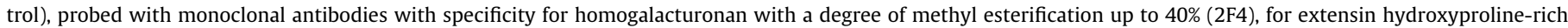
glycoproteins (LM1), for 1,4- $\beta$-galactan (LM5) and 1,5- $\alpha$-arabinan (LM6). In each row the antibody was used to probe samples at a 1:5 sequential dilution.

model described, we observed that during the first 3 weeks of development, callus growth was impaired by the absence of phosphates and sulfates (Fig. 1). Callus from plates depleted in nitrates was less affected, probably due to previous nitrogen accumulation, since the nitrate concentration in the MS medium is much higher than those of phosphate or sulfate. By the sixth week, in the second culture cycle, the callus growth was drastically reduced to levels significantly lower than those observed at -P and similar to -S (Fig. 1). The collective results confirm the essential role of these elements and validate the experiment model employed to access the effect of mineral nutrition in CW constituents and dynamics. Previous studies also report the effect of mineral depletion on growth [24,60], including of Vitis callus [23].

Our goal was to address changes in CW composition triggered by mineral deficiency. FT-IR proved to be a readily employed and efficient method for simultaneously identifying a broad range of structural differences in CWs [36]. The overall FT-IR results suggest changes in all of the main components of the CW as candidate events, such as modifications in the biosynthesis or rearrangements of cellulose microfibrils and of matrix linked glycans, in pectin bio-

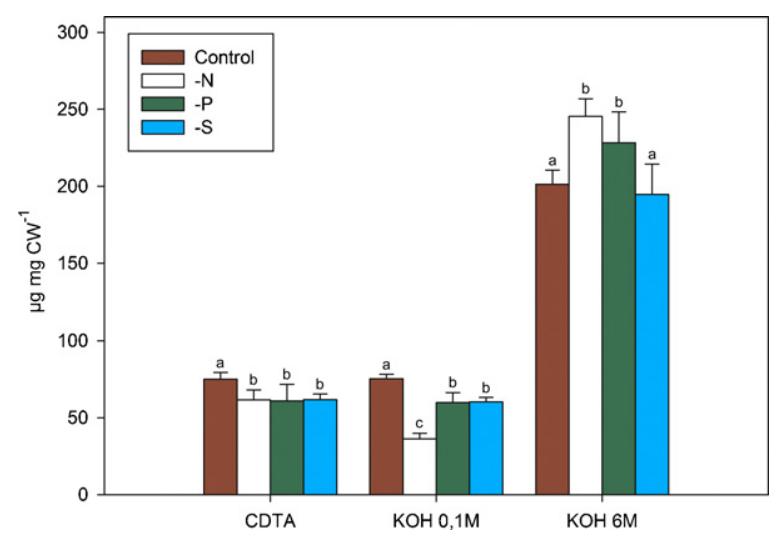

Fig. 6. Total sugars quantified in $\mathrm{CW}$ fractions obtained from callus grown for 6 weeks in the absence of nitrogen $(-N)$, phosphorus $(-P)$, sulfur $(-S)$ and in full nutrient media (Control). Units are $\mu \mathrm{g}$ of glucose equivalents $(\mathrm{mg} \mathrm{CW})^{-1}$. Bars represent means of 6 replicates \pm SD. In each sub-graph, different letters within each four bar block indicate significant differences at $p=0.05$. chemistry and in the amounts of structural proteins (Figs. 2b and 3). Moreover, PCA analysis (Fig. 2a) showed that CW is differentially affected, according to the specific stress imposed. These results prompted us to pursue a more detailed biochemical analysis of the stressed material.

The statistically significant reduction in cellulose content observed under $-\mathrm{N}$ and $-\mathrm{P}$ (Fig. 4a) could compromise the CW integrity and, probably, the viability of the cells to survive. Due to the paramount importance of the CW in survival and environment adaptation, plants are equipped with compensatory alternative mechanisms to reinforce their CWs when the biosynthesis or deposition of a given component is impaired $[61,62]$. Our results agree with such model. In fact, CWs from callus growing in medium exhausted in nitrates respond to low levels of cellulose (Fig. 4a) by slightly increasing their lignin content (Fig. 4b) and reducing their degree of pectin methyl esterification (Fig. 4c). If occurring in long stretches of the galacturonic acid chains as suggested by immunodot detection with the 2F4 antibody (Fig. 5), it could lead to reinforce the wall via the formation of calcium bridges, e.g. "egg-box" structures [63] and supramolecular pectic gels, both important in controlling the porosity and mechanical properties of CW and maintenance of intercellular adhesion $[4,64]$. Moreover, an expected looser cellulose network prods arabinancontaining polysaccharides to become more cross-linked to the cellulose-hemicellulose network (Fig. 7b and c), providing the wall with additional mechanical support and instigates the formation of extensin networks (Fig. 5). Likewise, the lower cellulose quantified in -P callus is accompanied by an increase in neutral sugars enriched in arabinose polysaccharides (Fig. 7b) including 1,5- $\alpha-$ arabinans (Fig. 5) detected in polysaccharides tightly bonded to the CW (Fig. 6).

Alterations in the biosynthesis of individual CW constituents can affect the synthesis and/or deposition of othe CW polymers. In fact, changes in the cellulose content are known to be compensated by an increase in lignin polymers. It was demonstrated that cinnamoyl-CoA reductase (CCR) down-regulation in transgenic tobacco (Nicotiana tabacum L.) lines lead to a $24.7 \%$ reduction of its Klason lignin with a concomitant increase of $15 \%$ in cellulose content [65]. Similarly, different works report that high nitrate availability reduces the lignin in the CW [66-68], so the opposite 


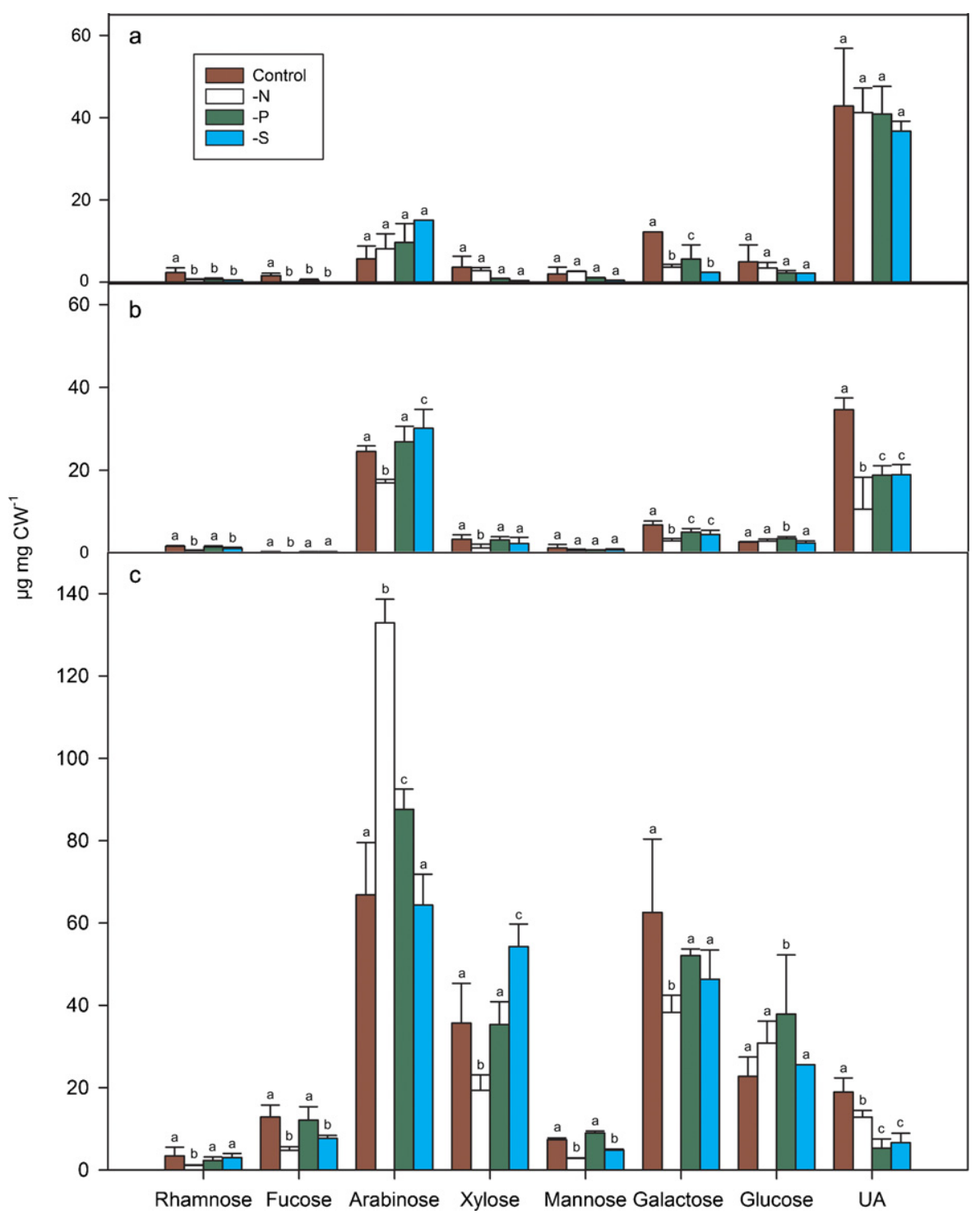

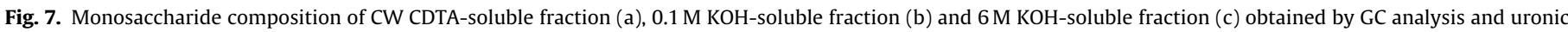

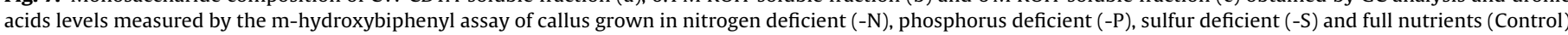

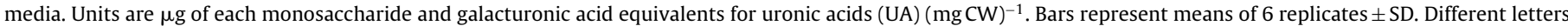
within each four bar block indicate significant differences at $p=0.05$.

trend is expected to happen. In fact, a mutation in CesA3, one of the genes encoding cellulose synthases, was proved to lead to CW reinforcement through lignin synthesis [69]. It has also been suggested that, under conditions where cellulose synthesis is inhibited, compensation with a higher quantity of hemicellulosic polysaccharides occurs [26]. Several other lines of evidence have demonstrated alterations in the CW architecture of the kor1-1 Arabidopsis mutant $[70,71]$, in which a deficiency in an endo-1,4- $\beta$-glucanase that is not directly implicated in pectin metabolism, induces a $150 \%$ increase of pectins in the primary CW [72]. Moreover, other cellulose synthase Arabidopsis mutant, MUR10/CesA7, showed an increase in pectic arabinan contents in response to impaired cellulose biosynthesis [73]. On the other hand, augmented arabinose levels may indicate a higher substitution by arabinosyl residues in the rhamnogalacturonan-I (RGI) side chains of pectic polysaccharides. RGI arabinosyl side chains can work as plasticizers in CWs that undergo large physical remodeling under abiotic stresses such as extreme water deficient conditions [74]. Ulvskov et al. [75] analyzed the mechanical properties of the CW of potato
(Solanum tuberosum) tubers from wild-type and transformed plants with decreased contents of arabinan and certified that the force needed to induce failure of the $\mathrm{CW}$ decreased in transgenic tubers.

Absence of sulfates in the media impaired callus growth in levels similar to those observed under nitrate deficiency (Fig. 1), but no significant reduction in cellulose was noticed (Fig. 4a). Nonetheless, among the assays conducted in our work, increases in weakly and tightly bonded extensins (Fig. 5) and increases in arabinose- and xylose-containing polysaccharides in alkali-soluble fractions (Fig. 7b and c) were detected, unveiling CW modifications. Extensins are abundant constituents of the primary CW [7], known to increase in response to several stresses [76-78]. These structural proteins have been implicated in the control of CW extension and strengthening by the formation of peroxidase-mediated intermolecular cross-links [38].

In summary, grapevine calluses submitted to individual mineral stresses are impaired on specific CW components or suffer reorganization of their deposition. Our results highlight that $V$. vinifera 
callus followed different strategies to overcome the adverse effects induced in the $\mathrm{CW}$ by the imposed mineral stress according to the severity perceived and its primary biological role, confirming previous assumptions that plants have evolved fine-tuned mechanisms to turn on different pathways related with specific wall components, in response to different stimulus.

\section{Acknowledgements}

The research was funded by Fundação para a Ciência e Tecnologia (FCT) Grant SFRH/BD/64047/2009 to JCF and CBAA (PestOE/AGR/UI0240/2011).

\section{References}

[1] S.C. Fry, Cross-linking of matrix polymers in the growing cell walls of angiosperms, Ann. Rev. Plant Physiol. 37 (1986) 165-186.

[2] S. Vorwerk, S. Somerville, C. Somerville, The role of plant cell wall polysaccharide composition in disease resistance, Trends Plant Sci. 9 (2004) 203-209.

[3] R. Zhong, Z.-H. Ye, Regulation of cell wall biosynthesis, Curr. Opin. Plant Biol. 10 (2007) 564-572.

[4] N.C. Carpita, D.M. Gibeaut, Structural models of primary cell walls in flowering plants: consistency of molecular structure with the physical properties of the walls during growth, Plant J. 3 (1993) 1-30.

[5] W.G. Willats, L. McCartney, W. Mackie, J.P. Knox, Pectin: cell biology and prospects for functional analysis, Plant Mol. Biol. 47 (2001) 9-27.

[6] L.F. Goulao, Pectin de-esterification and fruit softening: revisiting a classical hypothesis, Stewart Postharvest Rev. 6 (2010) 1-12.

[7] A.M. Showalter, Structure and function of plant cell wall proteins, Plant Cell 5 (1993) 9-23.

[8] D.J. Cosgrove, Assembly and enlargement of the primary cell wall in plants, Annu. Rev. Cell Dev. Biol. 13 (1997) 171-201.

[9] W. Boerjan, J. Ralph, M. Baucher, Lignin biosynthesis, Annu. Rev. Plant Biol. 54 (1993) 519-546.

[10] R. Vanholme, K. Morreel, J. Ralph, W. Boerjan, Lignin engineering, Curr. Opin. Plant Biol. 11 (2008) 278-285.

[11] D.J. Cosgrove, Wall structure and wall loosening. A look backwards and forwards, Plant Physiol. 125 (2001) 131-134.

[12] A. Zykwinska, J.F. Thibault, M.C. Ralet, Organization of pectic arabinan and galactan side chains in association with cellulose microfibrils in primary cell walls and related models envisaged, J. Exp. Bot. 58 (2007) 1795-1802.

[13] Z.A. Popper, S.C. Fry, Widespread occurrence of a covalent linkage between xyloglucan and acidic polysaccharides in suspension-cultured angiosperm cells, Ann. Bot. 96 (2005) 91-99.

[14] S.E. Marcus, Y. Verhertbruggen, C. Hervé, J.J. Ordaz-Ortiz, V. Farkas, H.L. Pedersen, W.G.T. Willats, J.P. Knox, Pectic homogalacturonan masks abundant sets of xyloglucan epitopes in plant cell walls, BMC Plant Biol. 8 (2008) 60 .

[15] T.J. Bootten, P.J. Harris, L.D. Melton, R.H. Newman, Solid-state NMR spectroscopy shows that the xyloglucans in the primary cell walls of mung bean (Vigna radiata L.) occur in different domains: a new model for xyloglucan-cellulose interactions in the cell wall, J. Exp. Bot. 55 (2004) 571-583.

[16] J. Hanus, K. Mazeau, The xyloglucan-cellulose assembly at the atomic scale, Biopolymers 81 (2006) 59-73.

[17] Y.B. Park, D.J. Cosgrove, A revised architecture of primary cell walls based on biomechanical changes induced by substrate-specific endoglucanases, Plant Physiol. 158 (2012) 1933-1943.

[18] G. Freshour, R.P. Clay, M.S. Fuller, P. Albersheim, A.G. Darvill, M.G. Hahn, Developmental and tissue-specific structural alterations of the cell-wall polysaccharides of Arabidopsis thaliana roots, Plant Physiol. 110 (1996) 1413-1429.

[19] N.M. Iraki, R.A. Bressan, P.M. Hasegawa, N.C. Carpita, Alteration of the physical and chemical structure of the primary cell wall of growth-limited plant cells adapted to osmotic stress, Plant Physiol. 91 (1989) 39-47.

[20] E. Shedletzky, M. Shmuel, T. Trainin, S. Kalman, D. Delmer, Cell wall structure in cells adapted to growth on the cellulose-synthesis inhibitor 2,6dichlorobenzonitrile: a comparison between two dicotyledonous plants and a Graminaceous Monocot, Plant Physiol. 100 (1992) 120-130.

[21] H. Mélida, P. García-Angulo, A. Alonso-Simón, A. Encina, J. Alvarez, J.L. Acebes, Novel type II cell wall architecture in dichlobenil-habituated maize calluses, Planta 229 (2009) 617-631.

[22] A. Amtmann, P. Armengaud, Effects of N, P, K and S on metabolism: new knowledge gained from multi-level analysis, Curr. Opin. Plant Biol. 12 (2009) 275-283.

[23] J. Fernandes, S. Tavares, S. Amâncio, Identification and exprexssion of cytokinin signaling and meristem identity genes in sulfur deficient grapevine (Vitis vinifera L.), Plant Signal. Behav. 4 (2009) 1128-1135.

[24] H. Tschoep, Y. Gibon, P. Carillo, P. Armengaud, M. Szecowka, A. Nunes-Nesi, A.R. Fernie, K. Koehl, M. Stitt, Adjustment of growth and central metabolism to a mild but sustained nitrogen limitation in Arabidopsis, Plant Cell Environ. 32 (2009) 300-318.
[25] X.F. Zhu, G.J. Lei, T. Jiang, Y. Liu, G.X. Li, S.J. Zheng, Cell wall polysaccharides are involved in P-deficiency-induced Cd exclusion in Arabidopsis thaliana, Planta 236 (2012) 989-997.

[26] G. Potters, T.P. Pasternak, Y. Guisez, K.J. Palme, M.A. Jansen, Stress-induced morphogenic responses: growing out of trouble, Trends Plant Sci. 12 (2007) 98-105.

[27] S.J. Palmer, D.M. Berridge, A.J.S. McDonald, W.J. Davies, Control of leaf expansion in sunflower (Helianthus annuus L.) by nitrogen nutrition, J. Exp. Bot. 47 (1996) 359-368.

[28] G. Taylor, A.J.S. McDonald, I. Stadenberg, P.H. Ereer Smith, Nitrate supply and the biophysics of leaf growth in Salix viminalis, J. Exp. Bot. 44 (1993) 155-164.

[29] N. Snir, P.M. Neumann, Mineral nutrient supply, cell wall adjustment and the control of leaf growth, Plant Cell Environ. 20 (1997) 239-246.

[30] J.W. Radin, M.P. Eidenbock, Hydraulic conductance as a factor limiting leaf expansion of phosphorus deficient cotton plants, Plant Physiol. 75 (1984) 372-377.

[31] E.S. Chapin, C.H.S. Walter, D.T. Clarkson, Growth response of barley and tomato to nitrogen stress and its control by abscisic acid, water relations and photosynthesis, Planta 173 (1988) 352-366.

[32] W. Guo, L. Zhang, J. Zhao, H. Liao, C. Zhuang, X. Yan, Identification of temporally and spatially phosphate-starvation responsive genes in Glycine max, Plant Sci. 175 (2008) 574-584.

[33] H. Takahashi, C.E. Braby, A.R. Grossman, Sulfur economy and cell wall biosynthesis during sulfur limitation of Chlamydomonas reinhardtii, Plant Physiol. 127 (2001) 665-673.

[34] L.F. Goulao, J.C. Fernandes, P. Lopes, S. Amâncio, Tackling the Cell Wall of the Grape Berry, in: H. Gerós, M. Manuela Chaves, S. Delrot (Eds.), The Biochemistry of the Grape Berry, Bentham eBooks, 2012, ISBN 978-1-60805-360-5, pp. 172-193.

[35] G. Mouille, S. Robin, M. Lecomte, S. Pagant, H. Hofte, Classification and identification of Arabidopsis cell wall mutants using Fourier-transform infrared (FT-IR) microspectroscopy, Plant J. 35 (2003) 393-404.

[36] A. Alonso-Simón, A.E. Encina, P. García-Angulo, J.M. Álvarez, J.L. Acebes, FTIR spectroscopy monitoring of cell wall modifications during the habituation of bean (Phaseolus vulgaris L.) callus cultures to dichlobenil, Plant Sci. 167 (2004) 1273-1281.

[37] J. Knox, Revealing the structural and functional diversity of plant cell walls, Curr. Opin. Plant Biol. 11 (2008) 308-313.

[38] P. Jackson, C. Galinha, C. Pereira, A. Fortunato, N. Soares, S. Amâncio, C. Pinto Ricardo, Rapid deposition of extensin during the elicitation of grapevine callus cultures is specifically catalysed by a $40 \mathrm{kDa}$ peroxidase, Plant Physiol. 127 (2001) 1065-1076.

[39] T. Murashige, F. Skoog, A revised medium for rapid growth and bioassays with tobacco tissue, Physiol. Plant. 15 (1962) 493-497.

[40] K.W. Talmadge, K. Keegstra, W.D. Bauer, P. Albersheim, The structure of plant cell walls I. The macromolecular components of the walls of suspensioncultured sycamore cells with a detailed analysis of the pectic polysaccharides, Plant Physiol. 51 (1973) 158-173.

[41] D.M. Updegraff, Semi-micro determination of cellulose in biological materials, Anal. Biochem. 32 (1969) 420-424.

[42] J.F. Saeman, W.E. Moore, M.A. Millet, Sugar units present. Hydrolysis and quantitativepaper chromatography, in: R.L. Whistler (Ed.), Methods in Carbohydrate Chemistry, Vol. 3, Cellulose, Academic Press, New York, 1963, pp. 54-69.

[43] Z. Dische, General color reactions, in: R.L. Whistler, M.L. Wolfran (Eds.), Carbohydrate Chemistry, Academic, New York, 1962, pp. 477-512.

[44] R.D. Hatfield, H.G. Jung, J. Ralph, D.R. Buxton, P.J. Weimer, A comparison of the insoluble residues produced by the Klason lignin and acid detergent lignin procedures, J. Sci. Food Agric. 65 (1994) 51-58.

[45] P.J. Wood, I.R. Siddiqui, Determination of methanol and its application to measurement of pectin methyl ester content and pectin methylesterase activity, Anal. Biochem. 39 (1971) 418-428.

[46] R.R. Selvendran, M.A. O'Neill, Isolation and analysis of cell walls from plant material, Methods Biochem. Anal. 32 (1987) 25-153.

[47] M. Dubois, K.A. Gilles, J.K. Hamilton, P.A. Rebers, F. Smith, Colorimetric method for determination of sugars and related substances, Anal. Chem. 28 (1956) 350-356.

[48] N. Blumenkrantz, G. Asboe-Hansen, New method for quantitative determination of uronic acids, Anal. Biochem. 54 (1973) 484-489.

[49] P. Albersheim, P.D. Nevins, P.D. English, A. Karr, A method for the analysis of sugar in plant cell wall polysaccharides by gas liquid chromatography, Carbohydr. Res. 5 (1967) 340-345.

[50] P. García-Angulo, W.G.T. Willats, A.E. Encina, A. Alonso-Simon, J.M. Alvarez, J.L. Acebes, Immunocytochemical characterization of the cell wall of bean cell suspenion cutures during habituation and dehabituation to doclobenil, Physiol. Plant. 127 (2006) 87-99.

[51] R.H. Wilson, A.C. Smith, M. Kačuráková, P.K. Saunders, N. Wellner, K.W. Waldron, The mechanical properties and molecular dynamics of plant cell wall polysaccharides studied by Fourier-transform infrared spectroscopy, Plant Physiol. 124 (2000) 397-405.

[52] M. Kačuráková, P. Capek, V. Sasinková, N. Wellner, A. Ebringerová, FT-IR study of plant cell wall model compounds: pectic polysaccharides and hemicelluloses, Carbohydr. Polym. 43 (2000) 195-203.

[53] M.Sekkal, V.Dincq, P. Legrand, J.P. Huvenne, Investigation of the linkages in several oligosaccharides using FT-IR and FT Raman spectroscopies, J. Mol. Struct. 349 (1995) 349-352. 
[54] M.A. Coimbra, A. Barros, D.N. Rutledge, I. Delgadillo, FTIR spectroscopy as a tool for the analysis of olive pulp cell-wall polysaccharide extracts, Carbohydr. Res. 317 (1999) 145-154.

[55] C.F.B. Séné, M.C. McCann, R.H. Wilson, R. Grinter, Fourier-transform Raman and Fourier-transform infrared spectroscopy an investigation of five higher plant cell walls and their components, Plant Physiol. 106 (1994) 1623-1631.

[56] F. Liners, J.J. Letesson, C. Didembourg, P. Van Cutsem, Monoclonal antibodies against pectin. Recognition of a conformation induced by calcium, Plant Physiol. 91 (1989) 1419-1424.

[57] M. Smallwood, H. Martin, J.P. Knox, An epitope of rice threonineand hydroxyproline-rich glycoprotein is common to cell wall and hydrophobic plasma-membrane glycoproteins, Planta 196 (1995) 510-522.

[58] L. Jones, G.B. Seymour, J.P. Knox, Localization of pectic galactan in tomato cell walls using a monoclonal antibody specific to $(1[\rightarrow] 4)$-[ beta]-D-galactan, Plant Physiol. 113 (1997) 1405-1412.

[59] W.G. Willats, S.E. Marcus, J.P. Knox, Generation of monoclonal antibody specific to $(1 \rightarrow 5)$-alpha-L-arabinan, Carbohydr. Res. 308 (1998) 149-152.

[60] P. Wu, L. Ma, X. Hou, M. Wang, Y. Wu, F. Liu, X.W. Deng, Phosphate starvation triggers distinct alterations of genome expression in Arabidopsis roots and leaves, Plant Physiol. 132 (2003) 1260-1271.

[61] E. Pilling, H. Höfte, Feedback from the wall, Curr. Opin. Plant Biol. 6 (2003) 611-616.

[62] S. Wolf, K. Hématy, H. Höfte, Growth control and cell wall signaling in plants, Annu. Rev. Plant Biol. 63 (2012) 381-407.

[63] M.C. Jarvis, Structure and properties of pectin gels in plant cell walls, Plant Cell Environ. 7 (1984) 153-164.

[64] J.P. Knox, Cell adhesion, cell separation and plant morphogenesis, Plant J. 2 (1992) 137-141.

[65] S. Prashant, M. Srilakshmi Sunita, S. Pramod, R.K. Gupta, S. Anil Kumar, S. Rao Karumanchi, S.K. Rawal, P.B. Kavi Kishor, Down-regulation of Leucaena leucocephala cinnamoyl CoA reductase (LICCR) gene induces significant changes in phenotype, soluble phenolic pools and lignin in transgenic tobacco, Plant Cell Rep. 30 (2011) 2215-2231.

[66] J.A. Entry, G.B. Runion, S.A. Prior, R.J. Mitchell, H.H. Rogers, Influence of $\mathrm{CO}_{2}$ enrichment and nitrogen fertilization on tissue chemistry and carbon allocation in longleaf pine seedlings, Plant Soil 200 (1998) 3-11.
[67] J.T. Blodgett, D.A. Herms, P. Bonello, Effects of fertilization on red pine defense chemistry and resistance to Sphaeropsis sapinea, For. Ecol. Manage. 208 (2005) 373-382.

[68] F.E. Pitre, B. Pollet, F. Lafarguette, J.E. Cooke, J.J. MacKay, C. Lapierre, Effects of increased nitrogen supply on the lignification of poplar wood, J. Agric. Food Chem. 55 (2007) 10306-10314.

[69] A. Caño-Delgado, S. Penfield, C. Smith, M. Catley, M. Bevan, Reduced cellulose synthesis invokes lignification and defense responses in Arabidopsis thaliana, Plant J. 34 (2003) 351-362.

[70] F. Nicol, I. His, A. Jauneau, S. Vernhettes, H. Canut, H. Höfte, A plasma membranebound putative endo-1,4- $\beta$-D-glucanase is required for normal wall assembly and cell elongation in Arabidopsis, EMBO J. 17 (1998) 5563-5576.

[71] S. Sato, T. Kato, K. Kakegawa, T. Ishii, Y.G. Liu, T. Awano, K. Takabe, Y. Nishiyama, S. Kuga, S. Sato, Y. Nakamura, S. Tabata, D. Shibata, Role of the putative membrane-bound endo-1,4-beta-glucanase KORRIGAN in cell elongation and cellulose synthesis in Arabidopsis thaliana, Plant Cell Physiol. 42 (2001) 251-263.

[72] I. His, A. Driouich, F. Nicol, A. Jauneau, H. Höfte, Altered pectin composition in primary cell walls of korrigan, a dwarf mutant of Arabidopsis deficient in a membrane-bound endo-1,4- $\beta$-glucanase, Planta 212 (2001) 348-358.

[73] S. Bosca, C.J. Barton, N.G. Taylor, P. Ryden, L. Neumetzler, M. Pauly, K. Roberts, G.J. Seifert, Interactions between MUR10/CesA7-dependent secondary cellulose biosynthesis and primary cell wall structure, Plant Physiol. 142 (2006) 1353-1363.

[74] J. Harholt, A. Suttangkakul, H. Vibe Scheller, Biosynthesis of pectin, Plant Physiol. 153 (2010) 384-395.

[75] P. Ulvskov, H. Wium, D. Bruce, B. Jorgensen, K.B. Qvist, M. Skjot, D. Hepworth, B Borkhardt, S.O. Sorensen, Biophysical consequences of remodeling the neutral side chains of rhamnogalacturonan I in tubers of transgenic potatoes, Planta 220 (2005) 609-620.

[76] A.M. Showalter, A.D. Butt, S. Kim, Molecular details of tomato extensin and glycine-rich protein gene expression, Plant Mol. Biol. 19 (1992) 205-215.

[77] C. Hirsinger, Y. Parmentier, A. Durr, J. Fleck, E. Jamet, Characterization of a tobacco extensin gene and regulation of its gene family in healthy plants and under various stress conditions, Plant Mol. Biol. 33 (1997) 279-289.

[78] A. Ueda, Y. Yamamoto-Yamane, T. Takabe, Salt stress enhances proline utilization in the apical region of barley roots, Biochem. Biophys. Res. Commun. 355 (2007) 61-66. 